\title{
Regulatory Competition in Network Interconnection Pricing
}

\author{
PER J. AGRELL * \\ Louvain School of Management and CORE, Université catholique de Louvain \\ JEROME POUYET \\ Department of Economics, Ecole Polytechnique France
}

\begin{abstract}
This paper covers network investment problems under decentralized control of regulation, infrastructure ownership and management. The model features two countries managing domestic infrastructures, used simultaneously for downstream international service provision. Initially, the welfare losses from non-cooperative investment financing policy and access pricing are derived. The impact of strategic interaction between the countries' access prices on the choice of financing policy is investigated. Under strict budget balancing, there are no incentives for efficiency improving investments. Further, investment coordination is shown useless in the absence of regulatory coordination. Illustrations from European network regulation policy for energy and rail are presented.
\end{abstract}

\section{Introduction}

One of the crucial consequences of the free mobility principle in the European Union is the establishment of an appropriately dimensioned infrastructure to enable the free circulation of information, energy, goods and human resources. Any impediments in the establishment, maintenance or continuous expansion of these infrastructures to support intra-community exchanges pose important policy problems in terms of integration, socioeconomic equity and market efficiency. Tight budget constraints in combination with an increased use of regional and international infrastructure for energy, road and rail transport have actualized the policy question concerning the interaction between network regulation and interconnection investment incentives. In particular, consider the deregulated markets for electricity, gas and rail transport that draw on capital intensive, nationally regulated and operated infrastructures (grids, corridors) to provide energy and services internationally. In the European setting, these latter services enjoy wide-ranging rights to access markets without barriers to the price, mode or type of services provided. However, the weak coordination of the financing and regulatory solutions for the networks has a real impact on the allocation of the fruits of the intracommunity trade, its rate of

\footnotetext{
* Contact Author. Center of Operations Research and Econometrics (CORE), Université catholique de Louvain, 34 Voie du Roman Pays, B-1348 Louvain-la-Neuve, BELGIUM. Fax: +32(0)10474301. E-mail: per.agrell@uclouvain.be
} 
expansion and the robustness of its financing solution. The objective of this paper is to address some of the policy issues in interconnection investment provision using a minimal model of regulatory competition in networks.

The flexible model that we describe below may be interpreted and applied in a range of institutional settings but we will provide a few illustrative examples to motivate its construction.

Electricity transmission. The backbone of the unbundled electricity network, ${ }^{1}$ the national high-voltage grid and the interconnections, is operated by transmission system operators (TSOs). In Europe, the TSOs are national entities subject to different regulatory regimes, ownership structures and operating conditions. The energy itself is only exchanged at a few trading places (such as Nord Pool and APX) under the direct supervision of the TSOs. The efficiency of these markets depends crucially on the ability and willingness of the TSOs to identify, relieve and manage the interconnections between grids. However, the national incentives and regulations facing the TSOs may provide ambiguous welfare effects. For example, the Scandinavian power exchange Nord Pool was created jointly by the Swedish TSO (Svenska Kraftnät) and the Norwegian TSO (Statnett $\mathrm{SF}$ ). The former is a publicly operated agency with soft budget constraints and a farreaching autonomy, whereas the latter is a profit-maximizing firm subject to a high-power incentive regime and national investment reviews. Currently, NordPool is $80 \%$ owned by the Nordic TSOs. In interconnected networks with trade, the different investment and financing modes clearly affect the organizational objectives of these managers. ${ }^{2}$

Road transportation. In road transport and highway infrastructure, we note that the financing solutions for ordering high-transit countries such as Austria, Germany and Switzerland differ in terms of share of public funding, variable and fixed tariffs. Contrasting the French situation (no fixed national road-use tariffs and high variable tolls) with the German solution (high national fees, introducing moderate transit fees in 2004), one may inquire whether the current regulatory interaction is plausible to induce a stable and unique access price equilibrium.

International railways. Finally, in railroads, the French charging system has enabled the national infrastructure manager (RFF) to recover only about $25 \%$ of its total cost, while cost recovery is $40 \%$ for the Austrian counterpart (SCHIG); on the other hand, the German access pricing system has been set with the aim of recovering all costs, excluding those related to new or enhanced infrastructure. In view of these differences, particular attention should be devoted to infrastructure access pricing for inter-network services, as emphasized in EC Directive 14/2001, which upholds that coordination across countries is required in order to avoid the negative impact of lacking harmonization of charging systems.

As we will show in this paper, the answers to these important policy questions are far from trivial and highly dependent on the incumbent institutional structure in the interfacing jurisdictions. Seen from a public economics viewpoint, our results can inform the debate

\footnotetext{
${ }^{1}$ See EC directive 2003/54/EC

${ }^{2}$ Another example relates to interconnections between the Netherlands and Germany, where a tightly regulated Dutch TSO (TenneT) under a high-powered revenue cap until 2004 was facing integrated firms enjoying very lax regulation. By contrast, Germany had no electricity regulator until July 2004. Here, the behaviour of the German counterparts, internalizing downstream market rents in their transit and grid tariffs, as well as capacity management, may have a significant impact of the social welfare on the competitive Dutch side. The six German TSOs controlled up to $85 \%$ of the generator capacity and up to $80 \%$ the national tariffs to captive households constituted (unregulated) access prices.
} 
on the costs and benefits of centralization vs. decentralization of infrastructure regulation in open trade zones such as the European Union.

In our model, which builds on Bassanini and Pouyet (2005), a downstream sector requires the access to two national networks to produce a final service. The consumers' surplus associated with the provision of the final good is shared between the two countries. In each country, an infrastructure manager is in charge of determining the level of subsidy and the access tariff for the domestic network which maximize domestic welfare while preserving the financial viability of the local infrastructure. Under non-cooperation across countries, two externalities are created because of the incomplete internalization both of the total consumers' surplus and of the total infrastructure costs associated to the downstream service. We show that these externalities typically push the local access prices up, leading to too high a price for the final service.

We prove that a multiplicity of equilibria typically emerges. Intuitively, the optimal access price set in one country depends on the expectations about the level of access price set by the other country: if one country anticipates a high access price in the rival country, then it will lead both to subsidize its infrastructure and to implement a high access price because it expects a low demand and consequently a low access revenue. The various equilibria can be ranked according to the equilibrium level of access prices paid by the downstream sector and the level of public funds provided to the national infrastructures. Interestingly, given that access prices are excessively distorted upwards, a configuration in which infrastructures earn positive profits is even possible; this arises in particular when one country does not value the consumers' surplus associated with the final service (a socalled "pass-through"” or "transit" country). Such a case would never arise if the countries were perfectly cooperating.

Although the multiplicity of equilibria may not be appealing from a theoretical standpoint, we argue that it depicts well the institutional variety that we observe in the regulation of network industries across Europe.

We then turn to the principal policy question in this paper, namely that of infrastructure investment. A simple two-stage game is introduced in which countries choose first the investment levels and then decide upon the infrastructure financing (that is, access prices and subsidies) policies.

We first show that if countries do not devote public funds to the financing of their domestic networks, then they have no incentive to invest in enhanced infrastructures. Intuitively, a strict budget balancing requirement leads to an unstable equilibrium in access prices; this property implies that any decrease of the best-response in access price in a given country, which would result from a lower infrastructure cost, is followed by a strong increase of the equilibrium access prices. The strict budget-balancing requirement affects the nature of the interaction between the access pricing decisions, which in turn affects the investment incentives.

We then show that provided that a stable equilibrium in access prices is obtained, the non-cooperative countries always have insufficient incentives to invest in their domestic networks with respect to the socially optimal investment levels. Hence, and not surprisingly, there would be some gain to coordinate the investment decisions at a supranational level.

However, we also show that coordinating the investment without a strong coordination of the corresponding access pricing decisions is unlikely to bring strong benefits. A coordinated investment decision would ideally attempt to correct for the distortion in the 
access prices that are created by the non-cooperative behavior of the countries at the second stage of the game; we show that this correction is limited in our context.

We conclude this section by discussing how our results can shed some light on the failure of recent European investment projects in the electricity industry.

While most of the paper assumes for tractability that the downstream sector behaves perfectly competitively, we relax this assumption in the last section. We consider a downstream monopolist that perfectly discriminates among the final consumers through non-linear pricing schemes. In that context, we also consider that non-linear access pricing schemes are used by the infrastructure managers.

We show that the distortion, at the margin, on access prices is eliminated. Intuitively, the perfectly discriminating downstream firm creates no efficiency loss and captures all the consumers' surplus; this surplus can be in turn recovered by the infrastructure managers through non-linear access tariffs. Under perfect cooperation, the networks are not shut down as long as the consumers' surplus at the socially optimal final price exceeds the infrastructure fixed costs. However, under non-cooperation, countries have to agree on the sharing of the consumers' surplus; this sharing in turn determines when each country finds it preferable to shut down its own network. We show that non-cooperation leads to shutdown more frequently than cooperation. While the shutdown of existing networks is relatively unlikely, our results can be re-interpreted in the following way: non-cooperative countries have to agree on the mere decision to build a new infrastructure which will be jointly used to provide international services. Even when there are no inefficiencies on (marginal) access prices due to non-cooperation (because of downstream perfect discrimination combined with non-linear access pricing schemes), there are gains to implement side-transfers between countries to ensure that socially profitable infrastructure projects are effectively undertaken.

Throughout the paper, we use the work on regulation under budget constraints, pioneered by Boiteux (1956) and Ramsey (1927) in a different context. We also refer to the literature on access pricing and interconnection, which has especially developed as regards the telecommunications sector; see for instance Laffont and Tirole (2000). Chang (1996) studies the problem of pricing access in a vertically separated industry but does not consider the issue of interconnection, which is central to our analysis. Armstrong (2001) analyzes two-way interconnection between telecommunications networks providing international calling services to captive consumers. Our work is focuses on the choice of the mode of regulation and on the linkage between access prices, financing systems and interactions across countries in presence of international services using domestic networks. As said earlier, our model extends the settings of Bassanini and Pouyet (2005) by first allowing more asymmetries across countries, and second, introducing investment and downstream market power.

\section{The model}

Consider two countries or regions denoted by $i=1,2 .{ }^{3}$ In country $i$, an infrastructure manager, denoted hereafter by $I M_{\mathrm{i}}$, is in charge of the regulation of a domestic network. Regulation encompasses both the pricing of the access to the infrastructure and the amount

\footnotetext{
${ }^{3}$ The notation refers to the regulatory autonomy and may apply to group of countries (Benelux), as well as regions (German Bundesländer).
} 
of public funds dedicated to the financing of the network: denoted by $a_{i}$ and $t_{i} \geq 0$ the unit access price and the amount of subsidy decide by $I M_{\mathrm{i}}$.

Downstream operators use both networks to provide a final service to end-users. We consider the simplest form of complementarity between networks, in which producing one unit of final service requires to use one unit of each infrastructure ${ }^{4}$ For instance, one could think of round-trip transportation services from one country to the other or electricity exchange across countries.

The downstream sector produces the final service at a constant unit cost $c_{d}$. The final demand function for the good is denoted by $q\left(\right.$.) (with $\left.q^{\prime}()<0.\right)$. We denote by $\eta(p)$ the elasticity of that demand with respect to the price $p$, that is, $\eta(p)=\frac{-q^{\prime}(p) p}{q(p)}$. Up to Section 5, the downstream sector is assumed to behave competitively, which arises when downstream operators wage fierce Bertrand-like competition. Hence, the price of the final service paid by end-users is equal to the perceived marginal cost of the downstream operators, or $p_{*}=a_{1}+a_{2}+c_{d}$.

The objective of the domestic regulator is to maximize domestic welfare defined as the sum of three terms: (i) the fraction of the net surplus associated to the final service which accrues to domestic consumers; (ii) the infrastructure profit; (iii) the fraction of downstream operators profit which benefits his citizens through, say, shareholding. We now describe these terms.

A salient feature of transborder services is that the benefits associated to these services are shared across countries. Consequently, we consider that country $i$ internalizes a fraction $\theta_{i} \in[0,1]$ of the total consumers' net surplus $S(q)$ when a total quantity $q$ of final service is produced.

In order to produce a quantity $q$ of the final service, downstream operators must obtain access to both networks. The corresponding cost of operating the infrastructure in country $i$ is given by $c_{u} q+k_{i}$, where $c_{u}$ is the infrastructure marginal cost and $k_{i}$ is the infrastructure fixed cost. In our setting, the revenue generated by the pricing of access in country $i$ is given by $a_{i} q$. On top of this access revenue, we consider that $I M_{i}$ is allowed to provide the domestic infrastructure with a subsidy $t_{i} \geq 0$; to capture the imperfection of the taxation system and the distortions that it generates in the rest of the economy in our partial equilibrium framework, we consider that there is a cost of levying public funds denoted $\lambda_{p f}>0$.

Finally, since downstream operators are assumed to behave competitively, their profit is always nil.

Summarizing, the problem of $I M_{\mathrm{i}}$ can be stated as follows (where $p_{*}=a_{1}+a_{2}+c_{d}$ ):

$$
\begin{gathered}
\max _{\left\{\mathrm{a}_{\mathrm{i}} \geq 0\right\}} \theta_{i} S\left(q\left(p_{*}\right)\right)-\left(1+\lambda_{p f}\right) t_{i}+\pi_{i}^{I M} \\
\text { s.t. }\left(\mathrm{BB}_{\mathrm{i}}\right): \pi_{i}^{I M} \equiv t_{i}+\left(a_{i}-c_{u}\right) q\left(p^{*}\right)-k_{i} \geq 0 .
\end{gathered}
$$

\footnotetext{
${ }^{4}$ More complex patterns of complementarities could be introduced without changing qualitatively the nature of our argument.
} 


\section{Competition between infrastructure managers}

We consider the game in which infrastructure managers choose non-cooperatively and simultaneously the access price and the level of subsidy dedicated to their respective infrastructures.

\subsection{Best-responses}

To characterize the best-response functions of the infrastructure managers, note that the level of infrastructure subsidy in, say, country $j$ does not directly affect the optimization problem faced by the infrastructure manager in country $i$; consequently, the equilibria of the game between the infrastructure managers can be found by focusing on each country's "pseudo reaction-function" in access price.

Two intuitions are worth emphasizing at this stage. First, the presence of externalities across countries implies that access prices are excessively distorted: each regulator has a monopoly position over his infrastructure and does not fully internalize neither the whole consumers' surplus, nor the total infrastructure costs associated to the final services. Although this double marginalization effect is standard, it raises an additional possibility in our context, namely the possibility that the infrastructure revenue is large enough to cover the infrastructure cost without any subsidy. Second, the benefit of providing the infrastructure with a subsidy and relieving the burden on the access price has to be weighed against its cost in terms of cost of public funds.

Taking these remarks into account and considering country $i$, we may distinguish three regimes. The formal derivation of these cases is relegated to Appendix 7.1. In particular, we need to impose the following assumption: ${ }^{5}$

Assumption 1. Define $\delta \equiv \frac{q q^{\prime \prime}-q^{\prime 2}}{q^{\prime 2}}$. In the relevant range, $\delta \leq \frac{1}{2-\left(\theta_{i}+\theta_{j}\right)}$.

The parameter $\delta$ relates to the log-concavity/convexity of the final demand and can be positive (the case of an iso-elastic demand), null (the case of an exponential demand) or negative (the case of a linear demand). The condition stated in Assumption 1 ensures that the best-responses of the infrastructure managers can be characterized by first-order conditions.

Regime 1: No subsidy and a profitable infrastructure. Suppose that the budget constraint is not binding in country $i$. Since transfers are socially costly, $I M_{i}$ has no incentives to provide his infrastructure with a subsidy. The access price set in that country is thus such that:

$$
a_{i}^{1}\left(a_{j}\right) \text { such that } \frac{\mathrm{a}_{\mathrm{i}}^{1}-c_{u}}{p_{*}}=\left(1-\theta_{i}\right) \frac{1}{\pi\left(p_{*}\right)} .
$$

Intuitively, consider the polar case in which country $i$ would not internalize any fraction of the whole surplus, that is, $\theta_{i}=0$. Then, $I M_{i}$ could be viewed as an "infrastructure monopoly" since it is only interested in the infrastructure profit and indeed, the optimal access pricing rule in that context looks like the standard monopoly pricing rule.

\footnotetext{
${ }^{5}$ Where it leads to no confusion, we omit arguments for simplicity.
} 
This regime occurs as long as the infrastructure profit in country $i$ remains positive, which depends on the level of access price anticipated in country $j$; intuitively, if $a_{j}$ remains sufficiently low, then the final price of international services is low and the demand is high, implying that the infrastructure in country $i$ can earn positive profits through the pricing of its access. ${ }^{6}$ Define by $\underline{a}_{j}$ the value of the access price in country $j$ such that the infrastructure profit in country $i,\left[a_{i}^{1}\left(\underline{a}_{j}\right)-c_{u}\right] a\left(a_{i}^{1}\left(\underline{a}_{j}\right)+\underline{a}_{j}+c_{d}\right)-k_{i}$ is nil; hence, Regime 1 occurs as long as $a_{j} \leq \underline{a}_{j}$.

Regime 2: No subsidy and no infrastructure profit. If the regulator in country $i$ anticipates a larger access price in the rival country, then the infrastructure in country $i$ is no longer profitable. Some upward distortion on $a_{i}$ is required to ensure that the budget-balance requirement is met.

Assume for the moment that $I M_{i}$ does not use public funds to cover the infrastructure costs, that is, $t_{i}=0$. Throughout the paper, we refer to such a situation as a "strict budget constraint" in country $i$, that is, $I M_{i}$ covers the infrastructure costs solely through access revenues and the budget-constraint binds. Denoting by $\lambda_{i} \geq 0$ the Lagrange multiplier associated to the strict budget constraint, the optimal access price in this case is characterized as follows:

$$
a_{i}^{2}\left(a_{j}\right) \text { such that } \frac{a_{i}^{2}-c_{u}}{p_{*}}=\frac{1+\lambda_{i}-\theta_{i}}{1+\lambda_{i}} \frac{1}{\eta\left(p_{*}\right)} .
$$

Intuitively, Regime 2 holds as long as the shadow cost of infrastructure financing through access pricing alone, embodied in $\lambda_{i}$, remains lower than the cost of public funds $\lambda_{p d f}$ Indeed, in those cases, from the viewpoint of $I M_{i}$ 's objective, it is less costly to finance the infrastructure with small distortions on his access price rather than with distortionary taxation.

In line with the intuition, we show in Appendix 7.1. that $\lambda_{i}$ is increasing in the access price set in country $j .{ }^{7}$ For future references, denote by $\bar{a}_{j}$ the value of the access price in country $j$ such that $\lambda_{i}\left(\overline{a_{j}}\right)=\lambda_{p f}$; hence, Regime 2 is valid as long as $\underline{a}_{j} \leq a_{j} \leq \bar{a}_{j}$.

Regime 3: Subsidy and no infrastructure profit. The third regime emerges when access pricing as the unique instrument to cover the infrastructure cost would provoke an excessive distortion on the access price, that is, when $a_{j} \geq \bar{a}_{j}$. In such a case, the infrastructure manager in country $i$ provides his infrastructure with a subsidy and the optimal access price is thus characterized as follows: ${ }^{8}$

$$
a_{i}^{3}\left(a_{j}\right) \text { such that } \frac{a_{i}^{3}-c_{u}}{p}=\frac{1+\lambda_{p f}-\theta_{i}}{1+\lambda_{p f}} \frac{1}{\eta}
$$

\footnotetext{
${ }^{6}$ It also depends on the level of infrastructure cost in country $i$. Notice that Bassanini and Pouyet (2005) implicitly rule out this case from the analysis by assuming simultaneously that the infrastructure fixed costs and the countries' valuations for the final service are high enough. By contrast, our analysis covers all the possible cases.

${ }^{7}$ A larger access price in country $j$ depreciates the demand for the final service and makes the strict budget constraint tighter in country $i$.

${ }^{8}$ For the ease of the exposition, we do not consider the uninteresting cases in which the access price anticipated by $I M_{\mathrm{i}}$ is so large that $I M_{\mathrm{i}}$ decides to shut down its network.
} 
This analysis shows that the level of access price and the financing system in one country depend on the expectations on the level of access price that will prevail in the neighbor country.

\subsection{Equilibria}

Summarizing, the best-response of country $i$ is characterized as follows:

$$
a_{i}=\left\{\begin{array}{l}
a_{i}^{1}\left(a_{j}\right) \quad \text { if } a_{j} \leq \underline{a}_{j}, \\
a_{i}^{2}\left(a_{i}\right) \quad \text { if } \underline{a}_{j} \leq a_{j} \leq \bar{a}_{j}, \\
a_{i}^{3}\left(a_{j}\right) \quad \text { if } a_{j} \geq \bar{a}_{j} .
\end{array}\right.
$$

For future references, it turns out to be useful to focus at the nature of the strategic interaction between access prices, that is, the slope of the infrastructure managers' reaction functions.

Lemma 1. The strategic interaction between access pricing decisions is characterized as follows:

$$
\frac{d a_{i}}{d a_{j}}=\left\{\begin{array}{cc}
\frac{\left(1-\theta_{i}\right) \delta}{1-(1-\theta) \delta} & \text { inRegime1 } \\
\frac{1+\lambda_{i}-\theta_{i}}{\theta_{i}} & \text { inRegime2 } \\
\frac{\left(1+\lambda_{p f}-\theta_{i}\right) \delta}{1+\lambda_{p f}-\left(1+\lambda_{p f}-\theta_{i}\right) \delta} & \text { inRegime3 }
\end{array}\right.
$$

Proof. See Appendix 7.1.

In the second regime, access prices are always strategic complements, that is, reaction functions are upward-sloping whatever the characteristics of the final demand. Intuitively, in that regime $I M_{i}$ complies to a strict budget balance constraint which thus fully characterizes its access price; if country $j$ increases its own access price, thereby depreciating the final demand and decreasing the infrastructure revenue in country $i, I M_{i}$ is forced to increase in turn his access price to satisfy the strict budget constraint.

In the other regimes, access pricing is less constrained (either because the budget constraint is not binding, or because the infrastructure manager uses an additional instrument, namely the subsidy) and depends on the final demand characteristics. In particular, under Assumption 1, when $\delta \leq 0$ (respectively $\delta \geq 0$, access prices are strategic substitutes (respectively, strategic complements) and best-responses are downward-sloping (respectively, upward-sloping).

We now have all the ingredients required to determine the equilibria of our game. In Figures 1 and 2, we draw the best-responses in access prices of the infrastructure managers and focus on the symmetric equilibria that emerge in symmetric situation (that is, $\theta_{i}=\theta_{j}$ and $\left.k_{i}=k_{j}\right)$. For future references, denote by $\left(a_{i^{*}}^{l}, a_{j^{*}}^{l}\right)$ the access prices at a symmetric equilibrium corresponding to Regime $l \in\{1,2,3\}$. 


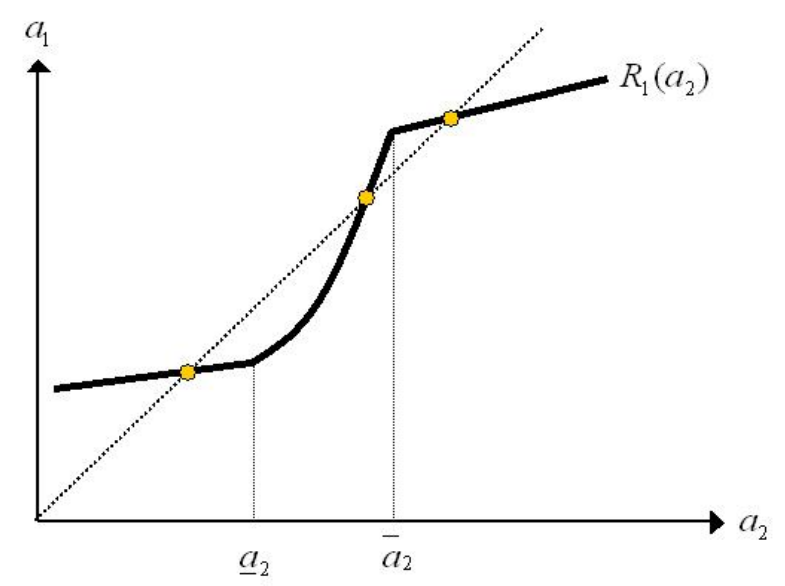

Figure 1: Symmetric equilibria in the case $\delta \geq 0$

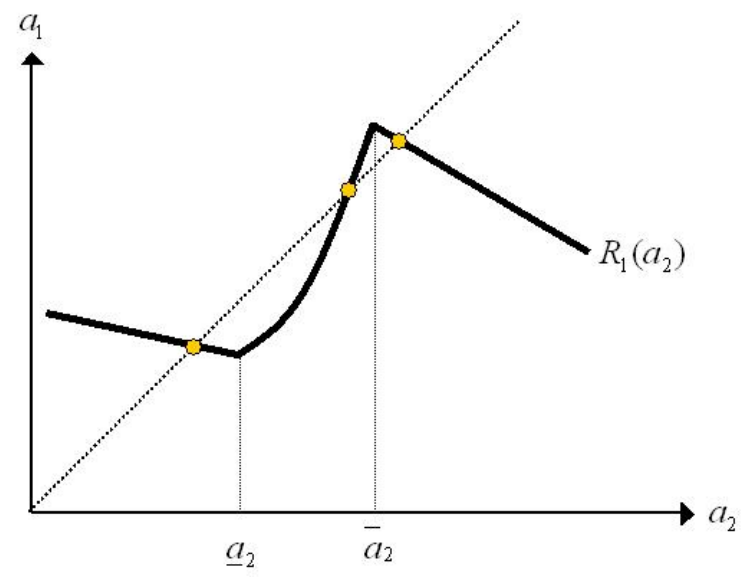

Figure 2: Symmetric equilibria in the case $\delta \leq 0$

\subsection{Discussions}

The social marginal cost of the downstream services is $c \equiv 2 c_{u}+c_{d}$. As a useful benchmark, consider the following situation: a centralized infrastructure manager maximizes the joint infrastructure profit, that is, $\max _{a}\left\{\left(a-2 c_{u}\right) q-\left(k_{i}+k_{j}\right)\right\}$, then simple computations show that the final price is given by the standard monopoly pricing formula, that is, $\frac{p_{*}-c}{p_{*}}=\frac{1}{\eta\left(p_{*}\right)}$ where $p_{*} \equiv a_{*}+c_{d}$. Indeed, since there is no market power at the downstream market 
power, the infrastructure monopoly can capture (through the access price) the whole industry profit.

Let us now return to our non-cooperative situation, in which the price for the final service depends on both access charges, that is, $p_{*} \equiv a_{i}+a_{j}+c_{d}$.

Let us first focus on Regime 1. Summing the corresponding first-order conditions, the final price that prevails in the downstream market is such that:

$$
\frac{p_{*}-c}{p_{*}}=\left[2-\left(\theta_{i}+\theta_{j}\right)\right] \frac{1}{\eta}
$$

Hence, when consumers' surplus is fully distributed across countries, that is, when $\theta_{i}+\theta_{j}=1$, the final price defined by (1) coincides with the final price that would prevail if the management of both infrastructures is delegated to a centralized profit-maximizing infrastructure manager. Moreover, when $\theta_{i}+\theta_{j}<1$ that is, when countries fail to fully internalize the social value associated to the downstream services, then non-cooperative regulation of the pricing of access leads to a final price above the monopoly price.

This striking comparison prompts for negotiations among national infrastructure managers. Note that those negotiations should bear not only on the level of national access prices, but also on the mode of financing chosen in the different countries since both are intrinsically intertwined.

Consider now Regimes 2 and 3. A quick inspection of Figures 1 and 2 shows that the total amount of access prices paid by the downstream sector in these regimes is larger than the corresponding amount in Regime 1. The intuition goes as follows: Regimes 2 and 3 reflect cases where it becomes more and more difficult to finance the networks in a given country because it expects a large access price to be set in the neighboring country. At equilibrium, when these expectations realize, there is indeed a strong need to distort the access prices. The interesting point to notice is that these different equilibria may co-exist, thereby creating a coordination problem between infrastructure managers. It turns out that under Assumption 1, the equilibria corresponding to Regimes 1 and 3 are stable in the sense of best-response dynamics. ${ }^{9}$ By contrast, the equilibrium corresponding to Regime 2 is always unstable.

So far, we have restricted our attention to equilibria in which both countries choose the same mode of financing for their network. Introducing various asymmetries, in the infrastructure costs for instance, may lead to asymmetric equilibria in which infrastructure managers adopt different regulatory regimes. Indeed, an increase in, say, the infrastructure fixed cost $k_{i}$ implies that $I M_{\mathrm{i}}$ 's best-response moves upward (as for a given $a_{j}$, ensuring the financing of infrastructure cost becomes more difficult).

Similarly, notice that the best-response of a transit country which does not value any fraction of the consumers' surplus (that is, $\theta_{i}=0$ for instance) always coincides with Regime 1. By contrast, the best-response of a country that values sufficiently consumers' surplus will always coincide to either Regime 2 or Regime 3. Hence, depending on differences in infrastructure costs and on surplus sharing among countries, asymmetric modes of network financing across countries can emerge as equilibria of our game.

\footnotetext{
${ }^{9}$ See Dixit (1986).
} 


\subsection{Institutional diversity}

The current institutional diversity in Europe may serve as illustration to the preceding analysis. Until June 2004, the European implementation of a common directive for energy markets varied considerably in both institutional and mechanism design. The market ranged from the German vertically integrated operators, subject to only ex post competition regulation, through ex post low-powered regulation in Sweden and Finland relying on vertical separation into hundreds of distribution utilities, to the British situation with highly incentivized operators. All these infrastructure managers are subject to nationally appointed regulatory authorities using different instruments and performance measures. The lack of regulatory coordination has been explicitly addressed by the European Commission through the official mandate allocated to the Council of European Energy Regulators (ERGEG) under the directives 2003/54 (electricity) and 2003/55 (gas). ${ }^{10}$ Under the new mandates, the European policy makers may refer directly to a coordinated viewpoint on energy network pricing and capacity promotion, rather than relying on bilateral contacts initiated by third parties (the infrastructure operators).

Concerning rail transport, we notice the differences in tariff policy between countries that are exporting vs. transiting international freight. Consider for example the fees charged by the Swedish rail infrastructure manager (Banverket) for freight transport, $0.00096 € / \mathrm{km} / \mathrm{ton}+258 €$ in toll for the border connection between Sweden and Denmark. ${ }^{11}$ The Danish counterpart (Banedanmark) charges $0.24 € / \mathrm{km}+285 €$ in toll for the interconnection, but in addition $940 €$ in toll for the Great Belt bridge in Denmark, necessary to transit goods by rail from Sweden to the continent. ${ }^{12}$ Without questioning the formal independence of the infrastructure managers, we notice the different importance of rail transport for the domestic operators in Denmark (dominated by the incumbent passenger operator DSB) and in Sweden (several independent private operators, dominated by freight transportation).

\section{$4 \quad$ Infrastructure investment incentives}

The purpose of this section is to study the countries' incentives to invest in infrastructure's enhancements, a matter of tantamount importance in network industries. A simple way to introduce investment in our framework goes as follows: at cost $\psi\left(y_{i}\right)$ (with $\psi($.$) strictly$ increasing and convex), country $i$ invests an amount $y_{i}$ to improve the cost efficiency of its infrastructure: for instance, if country $i$ invests an amount $y_{\mathrm{i}}$, then the marginal infrastructure cost of its network is given by $c_{u i}\left(y_{i}\right)$ (with $c_{u i}($.$) (strictly decreasing and$ concave). Since investment decisions are long-term engagements, we consider a two-stage game described as follows:

- $\quad$ First, the countries choose non-cooperatively the levels of investment dedicated to their networks.

\footnotetext{
${ }^{10}$ See Commission Decision of 11 November 2003 on establishing the European Regulators Group for Electricity and Gas, ERGEG.

11 2003, excluding tax, accident fees and fuel.

12 2003, excluding tax, accident fees and fuel.
} 
- $\quad$ Second, the infrastructure managers choose the infrastructure financing policies dedicated to their respective infrastructure.

The access prices setting stage has been considered in the previous section. Hence, we focus directly on the first stage of our game.

\subsection{The 'no investment curse' under strict budget constraints}

We start our analysis of infrastructure investment by focusing on the situation in which the infrastructure managers do not provide any public funds to their networks and the infrastructure budgets just break even. Hence, with regards to access prices, we are considering Regime 2 studied in the previous section.

The corresponding welfare in country $i$ for given levels of infrastructure investments can be obtained as: ${ }^{13}$

$$
W_{i}^{2}=\theta_{i} S\left(q\left(a_{i^{*}}^{2}+a_{j^{*}}^{2}\right)\right)
$$

Considering that the countries behave non-cooperatively at the first-stage of the game, the problem of country $i$ at the first stage of the game can thus be written as follows:

$$
\max _{y_{i}}\left\{W_{i}^{2}-\psi\left(y_{i}\right)\right\}
$$

Let us focus on the first-order condition:

$$
\frac{d}{d y_{i}}\left[W_{i}^{2}-\psi\left(y_{i}\right)\right]=\left[-\theta_{i} q\left(1+\frac{d a_{j}^{2}}{d a_{i}}\right) \frac{d a_{i^{*}}^{2}}{d c_{u i}}\right] c_{u i}^{\prime}\left(y_{i}\right)-\psi^{\prime}\left(y_{i}\right) .
$$

Condition (2) simply states marginal benefits and costs of investment. The marginal gain exerts both a direct effect on the access price set in that country, through a reduction of the marginal infrastructure cost, and a strategic effect, through the change of access price set in country $j$ following a change of access price set in country $i$. If country $i$ changes marginally its access price by an amount $d a_{i}^{2} / d c_{u i}$, then the final price is modified by $\left(1+d a_{j}^{2} / d a_{i}^{2}\right) d a_{i}^{2} / d c_{u i}$, which yields a variation in the net surplus of consumers of country $i$ given by the bracketed term on the left-hand side of (2).

Since access prices are strategic complements under a binding strict budget constraint, it suffices to focus on the sign of $d a_{i}^{2} / d c_{u i}$. Totally differentiating the binding strict budget balance condition in country $j$ and rearranging terms using the first-order conditions corresponding to Regime 2 leads to:

$$
\frac{d a_{i}^{2}}{d c_{u i}}=\left[1-\frac{1+\lambda_{i}-\theta_{i}}{1+\lambda_{j}} \frac{1+\lambda_{j}}{\theta_{j}}\right]^{-1}
$$

\footnotetext{
${ }^{13}$ With a slight abuse of notation, we define $a_{i^{*}}^{2}$ and $a_{j^{*}}^{2}$ as the access prices that result when both infrastructure managers choose not to subsidize their network and the strict budget constraints are binding and when network marginal costs are $c_{u i}\left(y_{i}\right)$ and $c_{u j}\left(y_{j}\right)$.
} 
Recall that under Regime 2 the multiplier associated to the strict budget constraint in a country must be positive. This observation allows us to prove immediately that the righthand side of (3) is negative for all admissible values of the multipliers, or:

$$
\frac{d a_{i}^{2}}{d c_{u i}}<0
$$

Consequently, reducing the marginal infrastructure cost in country $i$, through an infrastructure investment in that country, leads to a negative impact on welfare in that country since the final price increases!

Another interesting way to understand this result goes as follows. Differentiation of the strict budget balance in country $j$ leads to:

$$
\frac{d a_{i}}{d a_{j}}=\frac{-\left(a_{j}-c_{u i}\right) q^{\prime}}{q+\left(a_{j}-c_{u j}\right) q^{\prime}} .
$$

The infrastructure profit in country $j$ is concave in $a_{j}$; under a strict budget constraint $I M_{j}$ sets the lowest access price consistent with the budget constraint and we have $q+\left(a_{j}-c_{u i}\right) q^{\prime}>0$. Differentiation of the strict budget constraint in country $i$ without rearranging terms with the first-order conditions leads to:

$$
\left[\frac{d a_{i}}{d c_{u i}}\right]^{-1}=q+\left(a_{i}-c_{u i}\right) q^{\prime}\left(1+\frac{d a_{i}}{d a_{j}}\right)=q \frac{q+\left(a_{i}+a_{j}-c_{u i}-c_{u j}\right) q^{\prime}}{q+\left(a_{j}-c_{u j}\right) q^{\prime}}
$$

Since in a non-cooperative equilibrium access prices are distorted above the centralized infrastructure monopoly level (which are characterized by $q+\left(a_{i}+a_{j}-c_{u i}-c_{u j}\right) q^{\prime}=0$ ), we obtain that $\left[\frac{d a_{i}}{d c_{u i}}\right]<0$. Hence, this counter-intuitive result emerges not only because infrastructure managers use a strict budget-balance constraint but also because their noncooperative behaviour strongly distorts upwards the access prices.

Hence, concerning the investment decision in country $i$, we obtain a corner solution in which that country chooses not to invest at all. At the equilibrium of the two-stage game, both countries end up not investing in infrastructure enhancements.

Proposition 1. Consider that countries do not provide public funds to finance their networks and that strict infrastructure budget constraints are binding. At a noncooperative equilibrium, countries choose not to invest in their respective infrastructure.

The intuition for Proposition 1 can be grasped by returning to our analysis of noncooperative access pricing undertaken in the previous section. We highlighted that under a binding strict budget constraint, access prices were strategic complements and that bestresponses were always violating the usual stability condition. Hence, a reduction of the 
marginal infrastructure cost in one country, which amounts to having the best-response in access price move downwards, leads to an increase in both access prices at equilibrium, and thus to a lower net consumers' surplus.

Proposition 1 clearly calls for a strong form of coordination of the infrastructure investment decisions across countries. However, the next proposition states another negative result.

Proposition 2. Assume that no countries provide public funds to finance their networks and that strict infrastructure budget constraints are binding. Assume that countries perfectly cooperate when deciding infrastructure investment levels but behave noncooperatively at the access pricing stage. Then, at equilibrium, no investment is undertaken.

Proof. The cooperative infrastructure manager faces the following problem:

$$
\max _{\left\{y_{i}, y_{j}\right\}}\left\{W_{i}+W_{j}-\psi\left(y_{i}\right)-\psi\left(y_{j}\right)\right\}
$$

where $W_{i}$ and $W_{j}$ have been defined previously. In an interior optimum, the first-order conditions are:

$$
-\left(\theta_{i}+\theta_{j}\right) q\left(1+\frac{d a_{j}^{2}}{d a_{i}}\right) \frac{d a_{i^{*}}^{2}}{d c_{u i}} c_{u i}^{\prime}\left(y_{i}\right)-\psi^{\prime}\left(y_{i}\right)=0, i \neq j .
$$

Applying an argument similar to the one used to prove Proposition 1, one immediately sees that a corner solution appears with no investment at equilibrium.

Taken together, Proposition 1 and 2 clearly show the strong interdependency between the decisions to invest in infrastructure enhancements and the decisions concerning the mode of financing of the domestic networks. Differently put, a strong coordination between countries to decide the amount of infrastructure investment dedicated to the national networks is useless in the absence of a strong coordination at the access pricing stage when infrastructure managers have committed to comply with a strict budget balance.

\subsection{Investment decisions under infrastructure financing with public funds}

We continue our study of the impact of infrastructure investment and consider the case in which network managers use public funds to finance their infrastructure (Regime 3). ${ }^{14}$ The best-response in access price in country $i$ is now given by $a_{i}^{3}\left(a_{j}\right)$; define $\left(a_{i^{*}}^{3}, a_{j^{*}}^{3}\right)$ and $p_{*}^{3}$ the corresponding equilibrium access and final prices respectively.

Under non-cooperation, the problem faced by country $i$ at the investment stage of the game is given by:

$$
\max _{y_{i}}\left\{W_{i}-\psi\left(y_{i}\right)\right\}
$$

\footnotetext{
${ }^{14}$ Results for the case of Regime 1 are qualitatively similar.
} 
where $W_{i} \equiv \theta_{i} S\left(q\left(p_{*}^{3}\right)\right)+\left(1+\lambda_{p f}\right)\left[a_{i^{*}}^{3}-c_{u i}\left(y_{i}\right)\right] q\left(p_{*}^{3}\right)$. Using the envelope theorem, the first-order condition is obtained as: ${ }^{15}$

$$
\frac{\partial W_{i}}{\partial y_{i}}+\underbrace{\frac{\partial W_{i}}{\partial a_{j}} \frac{d a_{j}^{3}}{d a_{i}} \frac{d a_{i^{*}}^{3}}{d c_{u i}} c_{u i}^{\prime}\left(y_{i}\right)}_{\text {direct effect }}=\psi^{\prime}\left(y_{i}\right)
$$

The direct effect corresponds to the impact of a marginal increase in the investment level on the infrastructure cost for fixed access prices: $\partial W_{i} / \partial_{i}=-\left(1+\lambda_{p f}\right) q c_{u i}^{\prime}>0$. Increasing the investment in country $i$ leads to a positive direct effect on the welfare in that country since the reduction of the marginal cost allows to reduce distortionary taxation.

The strategic effect accounts for the impact of a change in the access price in country $i$ on the access price set in the bordering country. We show in Appendix 7.2 the following results:

- $\quad$ welfare in country $i$ decreases with the access price set in country $j$, or $\partial W_{i} / \alpha_{j}<0$;

- $\quad$ reduction of the marginal infrastructure cost in country $i$ leads to a smaller access price set in that country, or $d a_{i^{*}}^{3} / d c_{u i}>0$.

The former result simply expresses the fact that a higher access price in country $j$ diminishes the demand for final services and thus reduces both the consumers' net surplus and the access profit in country $i$; the latter result confirms the intuition. ${ }^{16}$

Consequently, the sign of the strategic effect is characterized by the sign of the strategic interaction, or refereeing to Lemma 1 , by the sign of $\delta$. Hence, when access prices are strategic substitutes (that is, when $\delta \leq 0$ ) country $i$ will be reluctant to invest much in infrastructure enhancement since this tends to increase the access price set in country $j$; a reverse result holds when access prices are strategic complements (that is, when $\delta \geq 0$ ).

In Appendix 7.2, we also show that the first-order condition (4) can be rewritten as follows:

$$
-c_{u i}^{\prime}\left(y_{i}\right)\left(1+\lambda_{p f}\right) q \frac{\left(1+\lambda_{p f}\right)-\left(1+\lambda_{p f}-\theta_{i}\right) \delta}{\left(1+\lambda_{p f}\right)-\delta\left[2\left(1+\lambda_{p f}\right)-\left(\theta_{i}+\theta_{j}\right)\right]}=\psi^{\prime}\left(y_{i}\right)
$$

In order to go further, let us also consider that the marginal infrastructure improvements due to investment are identical across countries, that is, $c_{u i}^{\prime}()=.c_{u j}^{\prime}($.$) . Then, Equation (5)$ shows that if country $i$ has a higher valuation for the final service than country $j$, that is, $\theta_{i} \geq \theta_{j}$, then the former country is willing to spend more in infrastructure investment than the latter if and only if access prices are strategic complements, that is, if $\delta \geq 0$.

Indeed, since the direct effect is the same for both countries, the differences in the investment incentives across countries stem from differences in the strategic impact of these investments. Now, assume for the sake of the exposition that access prices are

\footnotetext{
${ }^{15}$ We neglect the second-order conditions; notice that when $\delta$ is constant (the case of a linear, exponential or iso-elastic demand, these conditions are satisfied.

${ }^{16}$ Remember though that this result holds because best-responses satisfy the stability property, as opposed to the case of Regime 2.
} 
strategic complements. Consider that $\theta_{i} \geq \theta_{j}$; this implies that country $j$, which internalizes a lower fraction of net the consumers' surplus, imposes a higher access price than country $i$. This, in turn, implies that the strategic reaction of country $j$ following a change in access price in country $i$ is larger than the strategic reaction of country $i$ since, loosely speaking, the higher the original level of the access tariff is, the more room there is to reduce the access price. Hence, the country with the larger valuation for the final services has a stronger incentive to invest since it anticipates a larger reduction of the access price set in the other country. When access prices are strategic substitutes, an opposite reasoning holds and the low-valuation country invests more than the high-valuation one.

Under cooperation, the investment levels are decided to maximize the sum of the countries' welfare given the non-cooperative behavior of infrastructure managers at the access pricing stage. Focusing on the investment in the infrastructure in country $i$, we obtain the following first-order condition:

$$
\frac{\partial W_{i}}{\partial y_{i}}+\left[\frac{\partial W_{i}}{\partial a_{j}} \frac{d a_{j}^{3}}{d a_{i}} \frac{\partial W_{j}}{\partial a_{i}}\right] \frac{d a_{i^{*}}^{3}}{d c_{u i}} c_{u i}^{\prime}\left(y_{i}\right)=\psi^{\prime}\left(y_{i}\right) .
$$

Comparing (4) and (6), we can easily prove the following proposition.

Proposition 3. Assume that infrastructure managers use public funds to finance their networks and behave non-cooperatively at the access price setting stage. Then, noncooperative infrastructure managers always under-invest with respect to the cooperative benchmark.

The previous proposition states that when deciding their investment levels, noncooperative countries do not account for the positive externality they generate on each other; hence, under-investment occurs at the non-cooperative equilibrium.

Proposition 4. The optimal investment levels under cooperation are identical across countries if and only if $c_{u i}()=.c_{u j}($.$) .$

Basically, this proposition states that when a supra-national authority has to decide how much to invest in the different countries, that decision is based solely on the impact of those investments on the network costs; if those impacts are identical, then no matter how countries value the final services, the supra-national authority should invest the same levels in both countries.

To understand this result, let us return to the first-order condition (6) and consider that access prices $\left(a_{i}, a_{j}\right)$ emerge from the second stage of the game. In that case, we have $\partial W_{i} / \partial a_{j}=-\theta_{i} q+\left(a_{i}-c_{u i}\right) q^{\prime}$ which is a priori different from $\partial W_{j} / \partial a_{i}=-\theta_{j} q+\left(a_{j}-c_{u j}\right) q^{\prime}$.

Hence, one would expect that the supra-national authority invests differently in the countries when countries have different valuations for the final services.

However, taking into account that countries set access prices non-cooperatively at the second stage of the game, it comes immediately that for the access prices $\left(a_{i^{*}}^{3}, a_{j^{*}}^{3}\right), \partial W_{i} / \partial a_{j}=\partial W_{j} / \partial a_{i}$. Hence, even though countries value the final service differently, the marginal impact of the access charge in one country on the welfare in the 
other country is equalized at the optimum of the second stage of our game. Thus, there is no need to differentiate investments levels in the first stage since the marginal noninternalized externalities are equal across countries. A striking illustration of this result concerns the case with a transit country $\theta_{j}=0$ whereas country $i$ fully internalizes the consumers' surplus (that is, $\theta_{i}=1$ ). In this extreme scenario, the cooperative infrastructure investment levels are identical across the two countries.

Broadly speaking, this means that coordination only at the investment level is not sufficient to correct for the non-internalized externalities across countries choosing noncooperatively their infrastructure financing policies.

This has the same flavor as Proposition 2.

\section{The creation of international groupings of network operators}

The European Directive on the liberalization of international passenger services grants access rights for international groupings of licensed railway undertakings to operate international services between their countries of origin and transit rights in other Member States. Individual Member States are free to prescribe wider access rights.

Despite nationally regulated infrastructures, the Nord Pool electricity market place is characterized by tendencies of consolidation at the downstream level, especially in Norway ( $57 \%$ of generation capacity share by the five largest firms). Further, the consolidation is European, with for example the largest energy (electricity and gas) retailer (EON) in Central Europe posing as the second largest energy retailer in the Nordic market. Naturally, these operators may exploit any regulatory inconsistencies to extract information rents.

Hence, it becomes of interest to study the situation in which downstream operators possess some market power. Given that the previous sections focused on perfectly competitive downstream operators, we now address the polar scenario in which those downstream firms perfectly coordinate their pricing decisions, that is, the downstream networks operators behave monopolistically.

In order to deal with market power and the corresponding potential efficiency losses, the infrastructure managers should adopt two-part access pricing schemes. Indeed, we know from the textbook monopoly example that correcting for the dead-weight loss associated to monopoly power can be achieved by subsidizing the monopoly at the margin to correct for the firm's incentive to contract its output. A similar logic applies in our regulated environment with the addition that the infrastructure regulator captures the downstream monopoly profit through the fixed-part of the access tariff in order to finance the infrastructure cost.

The analysis of downstream market power can be undertaken under two alternative scenarios, which differ according to the pricing scheme adopted by the downstream monopoly.

Under linear pricing, downstream market power indeed generates an efficiency loss, which is corrected by subsidizing (that is, pricing access below the infrastructure marginal cost) the firm at the margin. However, since non-cooperative network managers do not fully internalize consumers' surplus and infrastructure costs, there still remain some inefficiencies in the access prices. The analysis of this case is straightforward and bears a 
strong resemblance to the case of perfect competition at the downstream level and will not be pursued further.

Alternatively, we could consider that the downstream monopoly price discriminates among the final consumers. In our complete information environment, perfect discrimination at the downstream level generates no efficiency loss: we show that allowing for discriminatory pricing both at the downstream and the upstream levels solves the inefficiencies on the setting of access prices that arise due to the non-cooperation between infrastructure managers; however, we also argue that non-cooperation between network managers gives rise to another kind of distortion.

Throughout this section, we consider that the downstream monopoly uses a two-part tariff of the form $p q+F$ and the infrastructure manager in country $i$ uses a two-part access pricing scheme of the form $a_{i} q+A_{i} \cdot{ }^{17}$

\subsection{Perfect cooperation with perfect downstream discrimination}

The monopoly's profit is given by

$$
\pi_{m}^{\text {down }}=\max _{\{p, F\}}\left\{\left[p-a-c_{d}\right] q(p)+F-A\right\} \text { s.t. }(I R): F \leq S(q)-\left(1+\lambda_{p f}\right) t,
$$

where $a$ and $A$ are the marginal access price and the fixed access fee imposed by the unique infrastructure manager. The monopoly cannot ask the consumers a fixed tariff $F$ larger than their net surplus; since consumers are also the taxpayers in our framework, that surplus must incorporate the taxes to finance the networks; hence the constraint (IR).

As usual, perfect discrimination calls for a marginal price equal to the perceived marginal cost of the monopoly (that is, $p_{m}=a+c_{d}$ ) while the fixed-part of the monopoly's tariff is set so as to capture all the consumers' surplus (that is, $\left.F_{m}=S(q)-\left(1+\lambda_{p f}\right) t\right)$ ). Thus, for a given access tariff, the downstream monopoly profit is equal to

$$
\pi_{m}^{\text {down }}=S\left(q\left(a+c_{d}\right)\right)-\left(1+\lambda_{p f}\right) t-A
$$

Importantly, notice that the perfectly-discriminating downstream monopoly fully internalizes consumers' surplus. Hence, provided that the downstream firm can perfectly discriminate among the consumers, there is no efficiency loss associated to downstream market power.

Let us step back to the common infrastructure regulator's problem. Total welfare can be written as follows:

$$
\begin{aligned}
& \max _{\{t \geq 0, a, A\}}\left[S(q)-F-\left(1+\lambda_{p f}\right) t\right]+\pi_{i}^{I M}+\alpha \pi_{m}^{\text {down }}, \\
& \text { s.t. } \pi^{I M}=t+\left(a-2 c_{u}\right) q\left(a+c_{d}\right)+A-\left(k_{i}+k_{j}\right) \geq 0 \\
& \pi_{m}^{\text {down }} \geq 0,
\end{aligned}
$$

where $\alpha \in(0,1)$ is the valuation for the downstream operators' profits. ${ }^{18}$ For consistency with the analysis undertaken previously, we maintain the (standard) assumption that the

\footnotetext{
${ }^{17}$ Since consumers are perfectly homogeneous, such a tariff is indeed sufficient to perfectly discriminate among the buyers.

${ }^{18}$ For instance, through shares held by the countries’ citizens in the downstream operators.
} 
downstream sector's rents are socially costly, which requires the downstream sector's profit be less valued than consumer's welfare in the regulator's objective function. Hence, the fixed part of the access tariff is set so as to leave the downstream monopoly with no rent.

The network manager's problem can thus be rewritten as follows:

$$
\begin{aligned}
& \max _{\{t \geq 0, a\}} \pi^{I M}, \\
& \text { s.t. } \pi^{I M}=t+\left(a-2 c_{u}\right) q\left(a+c_{d}\right)+A-\left(k_{i}+k_{j}\right) \geq 0 \\
& A=S\left(q\left(a+c_{d}\right)\right)-\left(1+\lambda_{p f}\right) t .
\end{aligned}
$$

The crucial feature is that the regulator can finance the infrastructure cost either with a subsidy or with the pricing of access; using public funds is costly whereas taxing the downstream sector through the pricing of access is not. Hence, in order to generate as much revenue as possible, the network manager sets a marginal access price equals to the infrastructure marginal cost, that is, $a=2 c_{u}$ and provides the infrastructure with no subsidy, that is, $t=0$. The final price coincides thus with the socially optimal price, that is, $p^{*}=2 c_{u}+c_{d}$.

Intuitively, perfect price discrimination by the downstream monopoly does not generate an efficiency loss; there is therefore no need to correct for the downstream monopoly market power. Second, the use of a two-part access pricing scheme allows redistributing profit from the downstream sector to the infrastructure at no cost. By contrast, using subsidy to finance the infrastructure entails some distortion which is captured by the shadow cost of public funds. Hence, since the regulator values equally consumers' surplus and the infrastructure revenue, it comes naturally that no subsidy is employed (since it reduces consumers' surplus, therefore the downstream profit gross of the fixed access fee) and that the downstream profit is fully captured by the fixed part of the access price and redistributed to the infrastructure. To conclude, we emphasize that the infrastructure is not shut down as long as the following condition holds:

$$
\text { No shut-down } \Leftrightarrow S^{*} \equiv S\left(q\left(p^{*}\right)\right) \geq k_{i}+k_{j} \text {. }
$$

This condition simply states that if the social value associated to the downstream services is below the infrastructure costs, then the networks should be shut down.

\subsection{Non-cooperation with perfect downstream discrimination}

The profit of the downstream operator is now given by

$$
\begin{aligned}
& \pi_{m}^{\text {down }}=\max _{\{p, F\}}\left\{\left[p-a_{i}-a_{j}-c_{d}\right] q(p)+F-\left(A_{i}+A_{j}\right)\right\} \\
& \text { s.t. } F \leq S(q)-\left(1+\lambda_{p f}\right)\left(t_{i}+t_{j}\right) .
\end{aligned}
$$

The monopoly still perfectly internalizes and captures the whole consumers' surplus; it therefore sets a marginal price equals to its perceived marginal cost, that is, $p=a_{i}+a_{j}+c_{d}$ and its profit is given by $\pi_{m}^{\text {down }}=S(q)-\left(1+\lambda_{p f}\right)\left(t_{i}+t_{j}\right)-\left(A_{i}+A_{j}\right)$. 
One can easily show that the infrastructure managers have no incentive to use subsidies to finance their infrastructure, that is, $t_{i}=t_{j}=0$. The problem faced by the infrastructure manager in country $i$ can be stated as:

$$
\begin{aligned}
& \max _{\left\{A_{i}, a_{i}\right\}} \pi_{i}^{I M}+\alpha_{i} \pi_{m}^{\text {down }}, \\
& \text { s.t. } \pi^{I M}=\left(a_{i}-c_{u}\right) q\left(a_{i}+a_{j}+c_{d}\right)+A_{i}-\left(k_{i} \geq 0,\right. \\
& \pi_{m}^{\text {down }}=S(q)-\left(A_{i}+A_{j}\right) \geq 0,
\end{aligned}
$$

where $\alpha_{i}+a_{j}=\alpha$. The infrastructure manager in country $i$ sets the fixed part of their access tariff to capture as much revenue as possible:

$$
\pi_{m}^{\text {down }}=0 \Leftrightarrow A_{i}+A_{j}=S(q)
$$

Thus, the optimization with respect to the marginal access price leads to $a_{i}=c_{u}$. Differently stated, non-cooperation between infrastructure managers does no longer create an inefficiency in the access price. Importantly, the downstream monopoly which perfectly discriminates among the consumers and fully internalizes consumers' surplus allows the non-cooperating network managers to coordinate their access pricing decisions.

Note that the sharing of the downstream profit between network managers is not defined in our context: Equation (7) only defines the sum of the access fees imposed by the network managers. ${ }^{19}$ To continue, assume that the sharing rule is such that: ${ }^{20}$

$$
A_{i}=\beta S^{*} \text { and } A_{j}=(1-\beta) S^{*} \text {. }
$$

Under non-cooperation, the infrastructure operation is continued as long as each network manager can ensure the financing of his own infrastructure, or:

$$
\beta S^{*} \geq \mathrm{k}_{\mathrm{i}} \text { and }(1-\beta) S^{*} \geq k_{j} .
$$

With respect to the perfect cooperation benchmark, we observe that these conditions are more restrictive than under perfect cooperation. Differently stated, non-cooperation leads more often to the shut-down of the shared infrastructure. While, under perfect cooperation, the infrastructure continues services as long as $S^{*} \geq k_{i}+k_{j}$, under non-cooperation it is operated if and only if the infrastructure fixed costs and the bargaining powers of the network managers are such that the conditions stated in (8) are met. This is illustrated in Figure 3.

\footnotetext{
${ }^{19}$ This highlights the multi-principals nature of our model.

${ }^{20}$ Certainly, this sharing depends on the bargaining power of one infrastructure manager with respect to the other.
} 


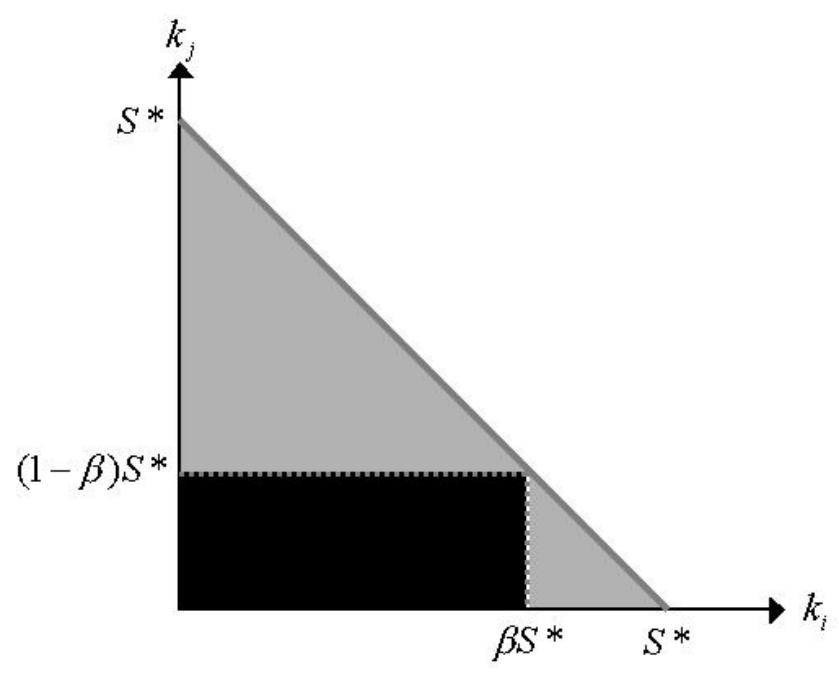

Figure 3: Decisions to operate the infrastructures or not

\subsection{Coordination in infrastructure investment decisions}

The analysis above can be interpreted in several different ways. In a first and direct reading, the analysis says that non-cooperative infrastructure managers, in their desire to extract as much rent as possible from the downstream sector, may trigger an unstable situation leading to the shut-down of the interconnection.

There is also a second reading, which is certainly more realistic. Indeed, one can add to the previous analysis a first-stage in which countries decide non-cooperatively to build a complementary fraction of the total shared network. Since it takes two to tango, the infrastructure is operational, if and only if, both countries choose to undertake their respective segments. Our analysis shows that in a number of instances, potentially Paretoimproving investments are not jointly implemented due to the non-cooperative behavior of the countries. Hence, the role for a supra-national entity that could assure the implementation by means of, for example, side-transfers among countries.

An interesting illustration of underinvestment by non-cooperative infrastructure managers is found on the French-Spanish border, a highly congested area between the high price Iberian Peninsula and the French power grid, dominated by competitive nuclear generation. ${ }^{21}$ European TEN-E funding for feasibility studies for several interconnection reinforcement has not lead to any realized investments in spite of encouraging results, lacking joint authorization from the regulatory authorities and mutual interest from the two infrastructure managers in France and in Spain. Here we also note the change of interest in interconnection capacity as the nationalized generator Electricité de France (EdF) took control of the fourth largest Spanish generator Hidrocantábrico in 2002. The Commission explicitly stated an investment in 2,700 MW increased interconnection capacity at the

\footnotetext{
${ }^{21}$ See, e.g. IAEW and CONSENTEC (2001)
} 
border as a condition to approve the acquisition. ${ }^{22}$ Note that the condition was jointly posed to the downstream generator EdF and the infrastructure manager in France (RTE), an explicit recognition of the imperfect separation between the interests of the infrastructure and the national downstream sector when facing investment tradeoffs. The Spanish government enforced the supra-national decision by regulatory rulings on their side against the generator.

The previous analysis shows that allowing for price discrimination both at the upstream and the downstream levels may soften the distortions on the access prices created by the non-cooperative behavior of the infrastructure managers. When the downstream sector performs first-degree discrimination and thus internalizes all the consumers' surplus, the network managers can advantageously use two-part access tariffs to capture the downstream profit, thereby internalizing the non-internalized externalities. This is in line with the discussion in Laffont and Tirole (2000, Chapter 3) on the rhetoric about fair and non-discriminatory access prices: in regulated environments, allowing for some form of price discrimination may sometimes be optimal. However, this result should be qualified: first, even though the marginal distortion of the access prices is removed (the marginal access prices are equal to the marginal infrastructure costs), another kind of distortion appears on the mere decision to run the networks. Second, price discrimination at the downstream level may be imperfect (because of asymmetric information for instance), thereby leading to only some efficiency losses and imperfect internalization of consumers' surplus between countries.

\section{Conclusion}

In this paper, we have modelled the interaction between network regulators who price the access to their respective infrastructure. These national networks are used as complementary inputs by downstream firms to produce transborder services. We found that the choice of equilibrium access prices and infrastructure financing systems is typically plagued by a multiplicity of equilibria, which calls for coordination between national network regulators. With regards to investments, we have shown that countries which commit to a strict budget balance financing system (that is, the access to the infrastructure is priced at the average infrastructure cost) have no incentives to invest in their networks; indeed, in that context a reduction of the infrastructure cost leads to an increase of both access prices once the strategic response by the neighboring country is properly taken into account. When countries finance their networks with a subsidy, an incentive to undertake some investment remains; however, countries typically tend to under invest compared to the socially optimal levels. In both cases, we argued that in order to improve welfare, some coordination by a supra-national authority is required; however, as our analysis suggests, for such coordination to be effective, it must address all dimensions of the regulatory interventions: the investment, the access pricing and the infrastructure subsidy decisions.

Our analysis is only a first step in the analysis of the institutional design of network industries. For instance, we have always considered that the network manager and its

\footnotetext{
${ }^{22}$ Cf. Commission Decision of 19 March 2002 and the Official Journal of 13 March 2004 (2004/C 65 E/161), p. 145-146. The Spanish government applied additional pressure by limiting the voting rights of EdF in the acquired firm until obtaining the investment commitment of the principal: the French government.
} 
political principal were merged into a unique entity. It would be interesting to relax this assumption and to investigate whether some form of vertical separation between the political principal and the infrastructure manager or some form of horizontal integration between national infrastructure managers becomes optimal. This is left for future research.

\section{$7 \quad$ References}

Armstrong, M. (2001) “The Theory of Access Pricing and Interconnection,” in M. Cave, S. Majumdar, I. Vogelsang (ed.), Handbook of Telecommunications Economics, NorthHolland, Amsterdam.

Bassanini, A. and J. Pouyet (2005) "Strategic Choice of Financing Systems in Regulated and Interconnected Industries,” Journal of Public Economics, 89: 233-259.

Boiteux, M. (1956) "Sur la Gestion des Monopoles Publics Astreints à l'Equilibre Budgétaire," Econometrica, 24: 22-40. Published in English as "On the Management of Public Monopolies Subject to Budgetary Constraints, Journal of Economic Theory, 1971, 3: 219-40.

Chang, M.C. (1996) "Ramsey Pricing in a Hierarchical Structure with an Application to Network-Access Pricing,” Journal of Economics, 64: 281-314.

Dixit, A. (1986) “Comparative Statics for Oligopoly,” RAND Journal of Economics, 27: 107-122.

Commission Decision of 19 March 2002 Declaring a Concentration to be Compatible with the Common Market (Case No IV/M.2684 - EnBW / EDP / CAJASTUR / HIDROCANTABRICO) according to Council Regulation (EEC) No 4064/89.

Directive 2001/14/EC of the European Parliament and of the Council of 26 February 2001 on the Allocation of Railway Infrastructure Capacity and the Levying of Charges for the Use of Railway Infrastructure and Safety Certification.

Directive 2003/54/EC of the European Parliament and of the Council of 26 June 2003 Concerning Common Rules for the Internal Market in Electricity and Repealing Directive 96/92/EC.

Directive 2003/55/EC of the European Parliament and of the Council of 26 June 2003 Concerning Common Rules for the Internal Market in Natural Gas and Repealing Directive 98/30/EC.

Hendricks, K., M. Piccione and G. Tan (1997) "Entry and Exit in Hub-spoke Networks," RAND Journal of Economics, 28: 291-303.

Institute of Power Systems and Power Economics (IAEW) and CONSENTEC (2001) "Analysis of Electricity Network Capacities and Identification of Congestion," Final Report for the European Commission, Directorate-General Energy and Transport. 
Laffont, J.-J. and J. Tirole (2000) Competition in Telecommunications. The MIT Press: Cambridge, Massachusetts.

Ramsey, F. (1927) “A Contribution to the Theory of Taxation,” Economic Journal, 37: 4761.

\section{$8 \quad$ Appendix}

\subsection{Competition between infrastructure managers}

Regimes 1 \& 3. Let us first consider Regime 1. Consider an interior solution of $I M_{\mathrm{i}}$ 's problem, in which $a_{i}$ is characterized by the following first-order condition: $a_{i}-c_{u}=\left(1-\theta_{i}\right) \frac{q}{-q^{\prime}}$. The local second-order condition amounts to $\delta \leq \frac{1}{1-\theta_{i}}$, which holds under Assumption1. Totally differentiating this condition with respect to $a_{i}$ and $a_{j}$ we obtain $\frac{d a_{i}}{d a_{j}}=\frac{\left(1-\theta_{i}\right) \delta}{1-\left(1-\theta_{i}\right) \delta}$. Hence, under Assumption 1, we have $\operatorname{Sign}\left[\frac{d a_{i}}{d a_{j}}\right]=\operatorname{Sign}[\delta]$. In order to ensure that the equilibrium corresponding to both infrastructure managers being in Regime 1 is stable, we need to assume that $\delta \leq \frac{1}{2-\left(\theta_{i}+\theta_{j}\right)}$, which corresponds to Assumption 1 .

Computations for Regime 3 are similar and immediately adapted. Notice that under Assumption 1, the local second-order condition, as well as the stability condition is met.

Regime 2. At the solution of $I M_{\mathrm{i}}$ 's problem, $\mathrm{a}_{\mathrm{i}}$ and $\lambda_{i}$ are characterized by

$$
\begin{aligned}
& a_{i}-c_{u}=\frac{1+\lambda_{i}-\theta_{i}}{1+\lambda_{i}} \frac{q}{-q^{\prime}} \\
& \left(a_{i}-c_{u}\right) q=k_{i} .
\end{aligned}
$$

Totally differentiating (10) with respect to $\mathrm{a}_{\mathrm{i}}$ and $\mathrm{a}_{\mathrm{j}}$ we get $\frac{d a_{i}}{d a_{j}}=\frac{1+\lambda_{i}-\theta_{i}}{\theta_{i}} \geq 0$. Totally differentiating (9) with respect to $\mathrm{a}_{\mathrm{i}}$ and $\lambda_{i}$, we obtain

$$
\frac{d \lambda_{i}}{d a_{j}}=\left[\frac{\theta_{i}}{1+\lambda_{i}} \frac{q}{-q^{\prime}}\right]^{-1}(1-\delta) \frac{1+\lambda_{i}-\theta_{i}}{\theta_{i}},
$$

which is positive under the Assumption 1. 


\subsection{Investment decisions under infrastructure financing with public funds}

Using the first-order condition with respect to $\mathrm{a}_{\mathrm{i}}$, simple manipulations show that:

$$
\begin{aligned}
\frac{\partial W_{i}}{\partial a_{j}}= & -\theta_{i} q+\left(1+\lambda_{p f}\right)\left(a_{i}-c_{u i}\right) q^{\prime}, \\
& =-\left(1+\lambda_{p f}\right) q<0 .
\end{aligned}
$$

Total differentiation of the first-order condition characterizing the optimal access price in country $i$, we obtain:

$$
\frac{d a_{i}}{d c_{u i}}=\frac{\left(1+\lambda_{p f}\right)-\left(1+\lambda_{p f}-\theta_{j}\right) \delta}{\left(1+\lambda_{p f}\right)-\delta\left[2\left(1+\lambda_{p f}\right)-\left(\theta_{i}+\theta_{j}\right)\right]},
$$

which is positive under Assumption 1. Hence, the sign of the strategic effect is given by the sign of the strategic interaction between access prices.

Finally, using the previous computations, one can immediately obtain Equation (5). 